\title{
Molar Incisor Hypomineralization-An Emerging Burden: A Short Study on Prevalence and Clinical Characteristics in Central Delhi, India
}

\author{
Mridula Goswami ${ }^{1}$, Urvashi Bhushan ${ }^{2}$, Ramanandvignesh Pandiyan ${ }^{3}$, Sadhna Sharma ${ }^{4}$
}

\begin{abstract}
Aim: To determine the prevalence of molar incisor hypomineralization $(\mathrm{MIH})$ in 6-12 years old children of the Central Delhi area.

Materials and methods: This cross-sectional descriptive short study consisted of 1,026 children aged 6-12 years selected by a random sampling procedure. The parents were interviewed and relevant prenatal, perinatal, and postnatal history was recorded. The dental examination was carried out by well-trained pediatric dentists. Full mouth examination of teeth was conducted including the European Academy of Pediatric Dentistry (EAPD) 2003 criteria for the diagnosis of $\mathrm{MIH}$. The results were documented and statistically analyzed using the Chi-square test.

Results: The prevalence of MIH was found to be $1.17 \%$. There was statistically significant difference in prevalence related to gender $(p<0.05)$ with a higher number of males affected with MIH. A total of 77 teeth ( 44 molars and 32 incisors) were observed with MIH. The severity of MIH was more in molars (52.27\%) when compared to incisors (24.24\%). All the four first permanent molars were affected in $83.3 \%$ of children with $\mathrm{MIH}$. Conclusion: The prevalence of $\mathrm{MIH}$ in a small sample of 1,026 children aged 6-12 years in Central Delhi was 1.17\%. A significant male predilection was reported. $\mathrm{MIH}$ is a developmental disturbance occurring during the maturation phase of enamel formation, which requires a multidisciplinary treatment approach. The high esthetic demand and the inability to deliver successful restorative care to the hypomineralized teeth can pose great difficulties. Hence, more studies related to prevalence, nature, and severity of $\mathrm{MIH}$ and awareness regarding the associated risk factors are required to reveal the hidden burden across the country and to further prevent the occurrence of $\mathrm{MIH}$.
\end{abstract}

Keywords: Masticatory functions, Molar incisor hypomineralization, Public health.

International Journal of Clinical Pediatric Dentistry (2019): 10.5005/jp-journals-10005-1624

\section{INTRODUCTION}

The decline in the occurrence of dental caries has encouraged many researchers to identify and distinguish other developmental disorders that were frequently neglected in the past. ${ }^{1}$ Isolated hypomineralized defects in enamel involving the first permanent molars (FPMs) and incisors presenting as discolored opacities or a total absence of enamel have gained considerable attention in the recent past.

Hypomineralized defects in enamel affecting FPMs were first noticed by a group of dentists in Sweden during the late 1970s. ${ }^{2}$ Weerheijm et al. recommended the term $\mathrm{MIH}$ at the Fifth Congress meeting of the European Academy of Pediatric Dentistry (EAPD) held in 2001. ${ }^{2}$ The definition of MIH as proposed by these authors described it as "hypomineralization of systemic origin affecting one to four FPMs, frequently associated with affected permanent incisors". 3 Since then, the term "Molar-Incisor Hypomineralization (MIH)" has been widely accepted and is used to describe sharply demarcated enamel defects, appearing yellow or brown in color, which are asymmetric in nature and are susceptible to breakdown under masticatory forces immediately after the eruption of the involved teeth. ${ }^{4} \mathrm{MIH}$ is said to be present if at least one FPM is involved, which may or may not be associated with the involvement of the incisors. ${ }^{5}$

The prevalence of $\mathrm{MIH}$ varies substantially across the world ranging from 2.8 to $40.2 \%{ }^{3}$ The highest prevalence was reported in Rio de Janeiro, Brazil followed by Sweden with least prevalence being reported in Hong Kong. ${ }^{4,6,7}$ A vast majority of studies on MIH have been conducted in the Northern Europe with the range varying between 3.6 and $25 \%$ [Weerheijm, 2004]. ${ }^{3}$ In India, the prevalence rate varies from 0.48 to $27 \%$ with the highest prevalence \begin{tabular}{l}
\hline${ }^{1-4}$ Department of Pedodontics and Preventive Dentistry, Maulana \\
Azad Institute of Dental Sciences, New Delhi, India
\end{tabular}

Corresponding Author: Sadhna Sharma, Department of Pedodontics and Preventive Dentistry, Maulana Azad Institute of Dental Sciences, New Delhi, India, Phone: +91 9650883536, e-mail: ssadhna265@ gmail.com

How to cite this article: Goswami M, Bhushan U, et al. Molar Incisor Hypomineralization-An Emerging Burden: A Short Study on Prevalence and Clinical Characteristics in Central Delhi, India. Int J Clin Pediatr Dent 2019;12(3):211-214.

Source of support: Nil

Conflict of interest: None

reported in the city of Udupi, South India. ${ }^{8}$ There are lacunae in the existing knowledge regarding $\mathrm{MIH}$ in Indian population.

$\mathrm{MIH}$ is a highly challenging developmental disturbance of permanent teeth presenting with altered masticatory functions and requires extensive treatment of the affected teeth soon after eruption. Hence, awareness about its associated risk factors and preventive measures can help to reduce the occurrence of $\mathrm{MIH}$ and dramatically decrease the burden of treatment cost.

The current study was conducted to determine the prevalence of MIH in 6-12 years old children of the Central Delhi area.

\section{Materials and Methods}

A cross-sectional short study was conducted in the Department of Pedodontics and Preventive Dentistry, Maulana Azad Institute

() The Author(s). 2019 Open Access This article is distributed under the terms of the Creative Commons Attribution 4.0 International License (https://creativecommons. org/licenses/by-nc/4.0/), which permits unrestricted use, distribution, and non-commercial reproduction in any medium, provided you give appropriate credit to the original author(s) and the source, provide a link to the Creative Commons license, and indicate if changes were made. The Creative Commons Public Domain Dedication waiver (http://creativecommons.org/publicdomain/zero/1.0/) applies to the data made available in this article, unless otherwise stated. 
of Dental Sciences, New Delhi. A sample of 1,026 children (534 boys and 492 girls) aged 6-12 years were randomly selected and screened for $\mathrm{MIH}$.

The dental examination was conducted by well-trained pediatric dentists in a dental chair. The teeth were examined under wet conditions and European Academy of Pediatric Dentistry (EAPD) 2003 diagnostic criteria were used to score defects involving FPMs and permanent incisors. ${ }^{9}$

A tooth with more than half of the clinical crown visible in the oral cavity was considered to have erupted. ${ }^{10}$ The teeth with white spot lesions, erosions, discoloration due to intake of tetracyclines, nonvitality, fluorosis, and defects with dimensions $<2 \mathrm{~mm}$ were excluded from the study. After the diagnosis of MIH was made, the affected teeth were recorded in the form of a master chart according to the individual tooth. The severity of hypomineralization was evaluated based on the criteria given by European Academy of Pediatric Dentistry. ${ }^{11}$

\section{Mild MIH}

Demarcated opacities in enamel without the evidence of enamel breakdown, sensitivity to stimuli such as air/water experienced infrequently without any sensitivity to tooth brushing, and discoloration of incisors presenting as a mild esthetic concern.

\section{Severe MIH}

Demarcated opacities in enamel associated with caries and enamel breakdown, sensitivity to external stimuli that affects function and is persistent/spontaneous and high aesthetic demands may have a socio-psychological impact.

Data obtained were subjected to statistical analysis using the Statistical Package for the Social Sciences (SPSS 20.0 version, Delaware, Chicago, IL, USA). The Chi-square test was used and $p$ value $<0.05$ was considered to be statistically significant.

\section{Results}

A total of 1,026 children were evaluated. Among them 534 were boys and 492 were girls. The mean age of the participants was 9.17 years (SD 1.17). The prevalence of MIH was $1.17 \%$. There was a statistically significant difference in prevalence related to gender $(p<0.05)$ with 11 out of 12 children affected with MIH being males (Table 1).

Table 1: Percentage of children with MIH

\begin{tabular}{llll}
\hline & Male n (\%) & Female $n(\%)$ & Total $n(\%)$ \\
\hline $\begin{array}{l}\text { Number of children } \\
\text { examined }\end{array}$ & $534(52.05 \%)$ & $492(47.95 \%)$ & $1026(100 \%)$ \\
$\begin{array}{l}\text { Number of children } \\
\text { with MIH }\end{array}$ & $11(1.07 \%)$ & $1(0.10 \%)$ & $12(1.17 \%)$ \\
\hline
\end{tabular}

Table 3: Individual prevalence of Mih in molars and incisors

\begin{tabular}{|c|c|c|c|c|c|c|}
\hline \multirow{3}{*}{$\begin{array}{l}\text { Teeth involved } \\
\text { with MIH }\end{array}$} & \multicolumn{4}{|c|}{$\mathrm{MIH}$} & \multirow[b]{3}{*}{ Total } & \multirow[b]{3}{*}{ Significance level } \\
\hline & \multicolumn{2}{|c|}{ Mild } & \multicolumn{2}{|c|}{ Severe } & & \\
\hline & $N$ & $\%$ & $N$ & $\%$ & & \\
\hline Molar & 21 & 47.73 & 23 & 52.27 & 44 & $p=0.013$ \\
\hline Incisor & 25 & 75.76 & 8 & 24.24 & 33 & \\
\hline
\end{tabular}

Table 4: Distribution of molars and incisors affected with Mih

\begin{tabular}{llllll}
\hline & \multicolumn{2}{l}{ Maxillan (\%) } & & \multicolumn{2}{l}{ Mandiblen (\%) } \\
\cline { 2 - 3 } \cline { 5 - 6 } Affected jaw & Incisors & Molars & & Incisors & Molars \\
\hline Left & $11(14.29)$ & $12(15.58)$ & & $5(6.49)$ & $10(12.99)$ \\
Right & $10(12.98)$ & $12(15.58)$ & & $7(9.09)$ & $10(12.99)$ \\
Total & $21(27.27)$ & $24(31.16)$ & & $12(15.58)$ & $20(25.98)$ \\
\hline
\end{tabular}

Table 5: Association of childhood illnesses and use of antibiotics during first year of life with Mih

\begin{tabular}{lll}
\hline Associated risk factor & Number of children & Significance level \\
\hline Childhood illnesses & 6 & $p=0.001$ \\
$\begin{array}{l}\text { Use of antibiotics in } \\
\text { first year of life }\end{array}$ & 2 & \\
\hline
\end{tabular}

A total of 77 teeth (33 incisors and 44 molars) were affected with $\mathrm{MIH}$. All the four FPMs were affected in 10 (83.3\%) children (Table 2). A majority of children (41.66\%) presented with the involvement of all the four FPMs and upper right and left permanent central incisors.

Table 3 shows the prevalence of $\mathrm{MIH}$ in molars and incisors individually. The severity of MIH was more in molars (52.27\%) when compared to incisors (24.24\%) and the difference between the two was statistically significant $(p<0.05)$. Mild MIH was more in incisors $(75.76 \%)$ when compared to molars $(47.73 \%)$ and the difference between the two was statistically significant ( $p=0.013$ ).

Table 4 shows the distribution of molars and incisors affected with $\mathrm{MIH}$ according to dental arch. A higher number of maxillary incisors (21) were affected in contrast with mandibular incisors (12). Also, mandibular molars (20) were less frequently involved as compared to maxillary molars (24).

Table 5 shows a significant association between childhood illnesses and use of antibiotics in the first year of life with $\mathrm{MIH}$ ( $p=0.001) .6$ out of 12 children with MIH were affected with childhood illnesses whereas two children presented with the intake of antibiotics during the first year of life. However, the parents of the affected children could not elicit the complete natal and postnatal history. Also, the relevant medical records regarding the type, dosage, and duration of antibiotics and various childhood illnesses could not be reproduced and might have resulted in an underestimation of the risk factors associated with $\mathrm{MIH}$.

Table 2: Distribution of children according to affected teeth

\begin{tabular}{|c|c|c|c|c|c|}
\hline \multirow{2}{*}{$\begin{array}{l}\text { Number of incisors } \\
\text { affected }\end{array}$} & \multicolumn{4}{|c|}{ Number of children with affected molars $n(\%)$} & \multirow[b]{2}{*}{ Totaln (\%) } \\
\hline & One molar & Two molars & Three molars & Four molars & \\
\hline 0 & 0 & 0 & 0 & 0 & 0 \\
\hline 1 & 0 & $1(8.33)$ & 0 & $1(8.33)$ & $2(16.66)$ \\
\hline 2 & 0 & $1(8.33)$ & 0 & $5(41.66)$ & $6(50)$ \\
\hline 3 & 0 & 0 & 0 & $1(8.33)$ & $1(8.33)$ \\
\hline 4 & 0 & 0 & 0 & $2(16.66)$ & $2(16.66)$ \\
\hline 5 & 0 & 0 & 0 & 0 & 0 \\
\hline 6 & 0 & 0 & 0 & $1(8.33)$ & $1(8.33)$ \\
\hline Total & 0 & $2(16.66)$ & 0 & $10(83.33)$ & 12 \\
\hline
\end{tabular}




\section{Discussion}

The aim of the present study was to determine the prevalence of $\mathrm{MIH}$ in 6-12 years old children of the Central Delhi area.

The majority of international studies of MIH have been conducted on children of European descent with a paucity of data pertaining to $\mathrm{MIH}$ in Indian populations. Therefore, prevalence studies on $\mathrm{MIH}$ are necessary since $\mathrm{MIH}$ is a demanding developmental disturbance of permanent teeth in the country.

The prevalence of $\mathrm{MIH}$ reported in our study (1.17\%) was relatively lower as compared to the data available from other Indian studies. ${ }^{1,3,8,12}$ The prevalence of $\mathrm{MIH}$ was found to be $9.4 \%$ in Udaipur, ${ }^{1} 9.2 \%$ in Gujarat, ${ }^{3}$ and $27 \%$ in Udupi. ${ }^{8}$

The relatively lower prevalence rate reported in our study could be due to strict adherence to the criteria given by the European Archives of Pediatric Dentistry, ${ }^{9}$ while recording $\mathrm{MIH}$.

The age range chosen in the study was 6-12 years with the aim to identify molars with hypomineralization soon after eruption limiting the chances of post eruptive enamel breakdown and caries initiation.

A significant male predilection was found in the study. A total of 12 children were affected with MIH out of which 11 were males. This was in agreement to studies conducted by Bhaskar et al. ${ }^{1}$ and Parikh et al., ${ }^{3}$ where a higher number of males were affected, although the difference was not statistically significant. Contrasting results were observed in a study conducted by Krishnan et al., ${ }^{13}$ where a higher number of females were affected with $\mathrm{MIH}$.

The criteria used for diagnosis was in accordance to that given by the European Archives of Pediatric Dentistry. ${ }^{9}$ The diagnosis of $\mathrm{MIH}$ was made when at least one permanent first molar was affected with or without the involvement of the permanent incisor. In the current study, 1,026 children were evaluated out of which 12 children are reported with $\mathrm{MIH}$. A total of 77 teeth were affected and a higher number of maxillary incisors and molars were involved when compared to the mandibular teeth. Various studies have reported a greater number of permanent maxillary first molar involvement., ${ }^{74-16}$ Contrasting results with the involvement of higher number of mandibular molars were reported by Subramaniam et al. ${ }^{17}$ The possible reason for the greater involvement of maxillary arch could be an earlier mineralization of upper molars as compared to lower molars leading to the exposure of upper molars to harmful agents at a more critical time period. Hence, a higher prevalence of hypomineralized defects may be noted in the maxillary arch.

A higher number of teeth $(59.7 \%)$ in the present study is presented with the mild form of $\mathrm{MIH}$. This finding is in congruence with other studies. ${ }^{3,16,18}$ The molars are presented with more severe form of MIH as compared to incisors. This may be due to an earlier eruption of molars making them more prone to the post eruptive enamel breakdown and development of caries. Out of 33 incisors, mild MIH was noted in 25 incisors with only 8 incisors presenting with severe $\mathrm{MIH}$.

$\mathrm{MIH}$ is considered to be result of systemic insult occurring during the maturation phase of amelogenesis manifesting as clinically visible enamel opacity. ${ }^{19}$ Various risk factors related to MIH include prenatal causes, such as maternal pyrexia, maternal diabetes, maternal nausea and vomiting, and use of myometrium spasmolytics. These causes can lead to abnormal oxygen levels and hypocalcemia altering the $\mathrm{pH}$ of the enamel matrix and inhibiting mineral deposition. The perinatal causes are related to the neonatal hypocalcemia, birth asphyxia, prolonged or complicated delivery, and elective cesarean section. ${ }^{19}$ Amongst the post natal causes, diseases of early childhood, such as chickenpox, otitis media, tonsillitis, high fever, gastrointestinal disorders, and frequent use of antibiotics, particularly in the first three years of life, are associated with $\mathrm{MIH}^{9,19-21}$ In our study, MIH was significantly associated with childhood illnesses and use of antibiotics in the first year of life. Since antibiotics are in most cases related to the occurrence of a disease, it becomes difficult to distinguish cases associated solely with the use of antibiotics from those related to the occurrence of various childhood illnesses or a combination of both the factors. ${ }^{9}$ In the current study, an underestimation of risk factors related to MIH might have resulted due to incomplete natal and postnatal history elicited by the parents of affected children and inability to procure relevant medical records giving information regarding the type, dosage and duration of antibiotics, and the exact nature of childhood illnesses.

A careful analysis of the results of this study necessitates that more studies be conducted to determine the prevalence, nature, and severity of $\mathrm{MIH}$ across the Indian subcontinent. As the burden of treatment cost is high with this developmental disorder, specific measures to prevent the occurrence of this defect seem to be the only solution. A thorough knowledge regarding the various associated risk factors and an early diagnosis can definitely help to reduce the morbidity associated with $\mathrm{MIH}$.

\section{Conclusion}

In the present study, the prevalence of MIH in 6-12 years old children of New Delhi is $1.17 \%$. A significant male predilection was reported. All the four FPMs were involved in $83.3 \%$ of the cases. $59.7 \%$ teeth presented with the mild form of $\mathrm{MIH}$ with molars were affected more frequently with the severe form. A significant association between childhood illnesses and use of antibiotics in the first year of life with MIH was seen.

A lack of knowledge and awareness about $\mathrm{MIH}$ and its related causes amongst the parents and affected children were noted during the course of this study. The relevant medical records regarding the type, dosage and duration of antibiotics, and various childhood illnesses could not be reproduced and might have resulted in an underestimation of the risk factors associated with $\mathrm{MIH}$.

$\mathrm{MIH}$ is a challenging developmental disturbance of permanent teeth requiring extensive treatment soon after eruption of affected teeth. The awareness about associated risk factors and development of preventive measures can help to reduce the occurrence of $\mathrm{MIH}$ and dramatically decrease the burden of treatment cost.

A paucity of data related to prevalence, nature, and severity of $\mathrm{MIH}$ necessitates that more studies should be conducted across the Indian subcontinent. An increased number of such studies will reveal the concealed burden of this disorder and help devise better preventive and therapeutic approaches for the management of $\mathrm{MIH}$.

Lastly, vigorous oral health campaigns focusing on generating awareness amongst the masses regarding such defects and their associated causes are the need in present times. The outcome of such programs can further be improved with an active involvement of pediatricians who can effectively cater to the health problems related to $\mathrm{MIH}$. They can provide precise knowledge of the various aspects related to the prevention and treatment of the childhood illnesses related to $\mathrm{MIH}$ and the judicious use of associated antibiotics. 
Hence, a consortium of pedodontists and pediatricians can help to generate awareness and reduce the burden of this developmental disorder.

\section{References}

1. Bhaskar SA, Hegde S. Molar-incisor hypomineralization: prevalence, severity and clinical characteristics in 8 to 13 year old children of Udaipur, India. J Indian Soc Pedod Prev Dent 2014;32(4):322-329. DOI: 10.4103/0970-4388.140960.

2. Martinovic B, Ivanovic $M$, et al. Prevalence, characteristics and severity of hypomineralization of the first permanent molars and incisors in children from the northern part of Kosovo and Metohija. Srp Arh Celok Lek 2017;145(78):364-369. DOI: 10.2298/ SARH160614056M.

3. Parikh DR, Ganesh M, et al. Prevalence and characteristics of Molar Incisor Hypomineralisation (MIH) in the child population residing in Gandhinagar, Gujarat, India. Eur Arch Paediatr Dent 2012;13(1):21-26. DOI: $10.1007 /$ BF03262836.

4. Soviero V, Haubek D, et al. Prevalence and distribution of demarcated opacities and their sequelae in permanent 1st molars and incisors in 7 to 13-year old Brazilian children. Acta Odontol Scand 2009;67(3): 170-175. DOI: 10.1080/00016350902758607.

5. Crombie F, Manton D, et al. Aetiology of molar incisor hypomineralization: a critical review. Int J Paediatr Dent 2009;19(2):73-83. DOI: 10.1111/j.1365-263X.2008.00966.X.

6. Jalevik B, Klingberg G, et al. The prevalence of demarcated opacities in permanent first molars in a group of Swedish children. Acta Odontol Scand 2001;59(5):255-260. DOI: 10.1080/000163501750541093.

7. Cho SY, Ki Y, et al. Molar incisor hypomineralization in Hong Kong Chinese children. Int J Paediatr Dent 2008;18(5):348-352. DOI: 10.1111/j.1365-263X.2008.00927.x.

8. Tadikonda AN, Acharya S, et al. Prevalence of Molar Incisor Hypomineralization and its Relation with Dental Caries in School Children of Udupi District, South India. J Dent 2015;6(3):143-146. DOI: 10.5005/jp-journals-10015-1330.

9. Weerheijm KL, Duggal $M$, et al. Judgement criteria for molar incisor hypomineralisation $(\mathrm{MIH})$ in epidemiologic studies: a summary of the meeting meeting on MIH held in Athens, 2003. Eur J Paediatr Dent 2003;4(3):110-113.
10. Ghanim A, Morgan M, et al. Molar-incisor hypomineralisation: prevalence and defect characteristics in Iraqi children. Int J Paediatr Dent 2011;21(6):413-421. DOI: 10.1111/j.1365-263X.2011.01143.x.

11. Lygidakis N, Wong F, et al. Best Clinical Practice Guidance for clinicians dealing with children presenting with Molar-Incisor-Hypomineralisation (MIH). Eur Arch Paediatr Dent 2010;11(2):75-81. DOI: 10.1007/ BF03262716.

12. Mittal NP, Goyal A, et al. Molar incisor hypomineralisation: prevalence and clinical presentation in school children of the Northern region of India. Eur Arch Paediatr Dent 2014;15(1):11-18. DOI: 10.1007/s40368-0130045-4.

13. Krishnan R, Ramesh M, et al. Prevalence and characteristics of MIH in school children residing in an endemic fluorosis area of India: an epidemiological study. Eur Arch Paediatr Dent 2015;16(6):455-460. DOI: 10.1007/s40368-015-0194-8.

14. Chawla N, Messer LB, et al. Clinical studies on molar-incisorhypomineralisation part 1: distribution and putative associations. Eur Arch Paediatr Dent 2008;9(4):180-190. DOI: 10.1007/BF03262634.

15. Weerheijm KL, Jalevik B, et al. Molar-incisor hypomineralisation. Caries Res 2001;35(5):390-391. DOI: 10.1159/000047479.

16. Lygidakis NA, Dimoun G, et al. Molar-incisor- hypomineralisation $(\mathrm{MIH})$. Retrospective clinical study in Greek children. I. Prevalence and defect characteristics. Eur Arch Paediatr Dent 2008;9(4):200-206. DOI: $10.1007 /$ BF03262636.

17. Subramaniam P, Gupta $T$, et al. Prevalence of molar incisor hypomineralization in 7-9-year-old children of Bengaluru City, India. Contemp Clin Dent 2016;7(1):11-15. DOI: 10.4103/0976-237X.177091.

18. YannamSD,Amarlal D, etal.Prevalence of molarincisor hypomineralization in school children aged 8-12 years in Chennai. J Indian Soc Pedod Prev Dent 2016;34(2):134-138. DOI: 10.4103/0970-4388.180438.

19. Garg N, Kumar Jain A, et al. Essentiality of Early Diagnosis of Molar Incisor Hypomineralization in Children and Review of its Clinical Presentation, Etiology and Management. Int J Clin Pediatr Dent 2012;5(3):190-196. DOI: 10.5005/jp-journals-10005-1164.

20. Dietrich G, Sperling S, et al. Molar incisor hypomineralisation in a group of children and adolescents living in Dresden (Germany). Eur J Paediatr Dent 2003;4(3):133-137.

21. JälevikB. Prevalence and diagnosis of molar-incisor-hypomineralisation (MIH): A systematic review. Eur Arch Paediatr Dent 2010;11(2):59-64. DOI: $10.1007 / \mathrm{BF} 03262714$. 